\title{
Arthur T. von Mehren und das internationale Zivilverfahrensrecht im transatlantischen Dialog
}

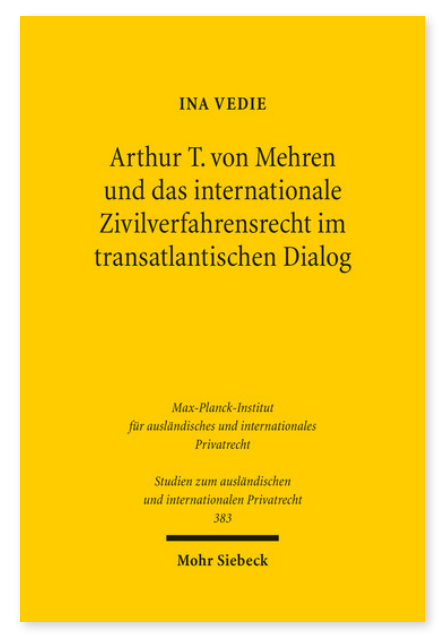

2017. XXVI, 417 Seiten. StudIPR 383

ISBN 978-3-16-155315-8

DOI 10.1628/978-3-16-155315-8

eBook PDF 74,00€

ISBN 978-3-16-155202-1

fadengeheftete Broschur 74,00€
Ein weltweites Übereinkommen auf dem Gebiet des internationalen Zivilverfahrensrechts kann nur Erfolg haben, wenn der transatlantische Dialog verbessert wird. Ina Vedie widmet sich diesem Dialog und rückt die Lehren des U.S.-Amerikaners Arthur Taylor von Mehren (1922-2006) in den Mittelpunkt der transatlantischen Rechtsvergleichung. Sie untersucht Fragen der internationalen Zuständigkeit, der grenzüberschreitenden Verfahrenskoordinierung und der Urteilsanerkennung. Dazu werden Entscheidungen des U.S. Supreme Court wie McIntyre v. Nicastro (2011) und Daimler v. Bauman (2014) herangezogen und grundlegende europäische Konzeptionen wie das Prinzip des actor sequitur forum rei und die Prioritätsregel für Parallelverfahren den amerikanischen Lösungsansätzen gegenübergestellt. Abschließend analysiert die Autorin den Einfluss von Mehrens auf die Arbeiten der Haager Konferenz für IPR vor dem Hintergrund des aktuellen Judgments Project.

Ina Vedie Geboren 1989; Studium der Rechtswissenschaft in Tübingen; 2014 Erste Juristische Prüfung; Stipendiatin der Landesgraduiertenförderung Baden-Württemberg; Akademische Mitarbeiterin am Lehrstuhl für Bürgerliches Recht, Internationales Privatrecht und Rechtsvergleichung an der Universität Tübingen; 2016 Promotion; seit 2016 Referendariat am Landgericht Frankfurt am Main.
Jetzt bestellen:

https://mohrsiebeck.com/buch/arthur-t-von-mehren-und-das-internationale-zivilverfahrensrecht-im-transatlantischen-dialog9783161553158?no_cache=1

order@mohrsiebeck.com

Telefon: +49 (0)7071-923-17

Telefax: +49 (0)7071-51104 